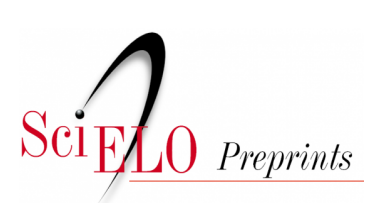

Situação: O preprint não foi submetido para publicação

\title{
Ciência e SUS no cotidiano: reflexões sobre a cobertura midiática durante a pandemia da COVID-19 no Brasil
}

Sheila Rodrigues de Souza, Leonor Maria Pacheco Santos, Ivana Cristina de Holanda Cunha Barreto, Antonia An Angulo-Tuesta, Luiz Odorico Monteiro de Andrade, Mauro Niskier Sanchez, Gabriela Oliveira da Silva

https://doi.org/10.1590/SciELOPreprints.2309

Este preprint foi submetido sob as seguintes condições:

- Os autores declaram que estão cientes que são os únicos responsáveis pelo conteúdo do preprint e que o depósito no SciELO Preprints não significa nenhum compromisso de parte do SciELO, exceto sua preservação e disseminação.

- Os autores declaram que os necessários Termos de Consentimento Livre e Esclarecido de participantes ou pacientes na pesquisa foram obtidos e estão descritos no manuscrito, quando aplicável.

- Os autores declaram que a elaboração do manuscrito seguiu as normas éticas de comunicação científica.

- Os autores declaram que os dados, aplicativos e outros conteúdos subjacentes ao manuscrito estão referenciados.

- O manuscrito depositado está no formato PDF.

- Os autores declaram que a pesquisa que deu origem ao manuscrito seguiu as boas práticas éticas e que as necessárias aprovações de comitês de ética de pesquisa, quando aplicável, estão descritas no manuscrito.

- Os autores concordam que caso o manuscrito venha a ser aceito e postado no servidor SciELO Preprints, a retirada do mesmo se dará mediante retratação.

- Os autores concordam que o manuscrito aprovado será disponibilizado sob licença Creative Commons CCBY.

- O autor submissor declara que as contribuições de todos os autores e declaração de conflito de interesses estão incluídas de maneira explícita e em seções específicas do manuscrito.

- Os autores declaram que o manuscrito não foi depositado e/ou disponibilizado previamente em outro servidor de preprints ou publicado em um periódico.

- Caso o manuscrito esteja em processo de avaliação ou sendo preparado para publicação mas ainda não publicado por um periódico, os autores declaram que receberam autorização do periódico para realizar este depósito.

- O autor submissor declara que todos os autores do manuscrito concordam com a submissão ao SciELO Preprints. 


\section{ENSAIO}

Ciência e SUS no cotidiano: reflexões sobre a cobertura midiática durante a pandemia da COVID-19 no Brasil

Science and SUS in daily life: reflections on media coverage during the COVID-19 pandemic in Brazil

Sheila Rodrigues Souza, Gabriela Oliveira da Silva, Antonia Angulo-Tuesta, Ivana Cristina de Holanda Cunha Barreto, Mauro Niskier Sanchez, Luiz Odorico Monteiro, Leonor Maria Pacheco Santos

Os aotores declaram que não há conflito de interesse.

ORCID autores: Sheila Rodrigues de Souza (https://orcid.org/0000-0001-9888-4315); Leonor Maria Pacheco Santos (https://orcid.org/0000-0002-6739-6260); Ivana Cristina de Holanda Barreto (http://orcid.org/0000-0001-8447-3654); Antonia An Angulo-Tuesta (https://orcid.org/0000-00023231-5918); Luiz Odorico Monteiro de Andrade (https://orcid.org/0000-0002-3335-0619); Mauro Niskier Sanchez (http://orcid.org/0000-0002-0472-1804); Gabriela Oliveira da Silva (https://orcid.org/0000-0001-5288-5427).

Os autores declaram a seguinte contribuição dos autores: Sheila Rodrigues de Souza: contribui na sua elaboração com as seguintes atividades: elaboração de versões preliminares do artigo ou revisão crítica de importante conteúdo intelectual; aprovação final da versão a ser publicada; concordância em ser responsável por todos os aspectos do trabalho, no sentido de garantir que as questões relacionadas à exatidão ou à integridade de qualquer parte da obra sejam devidamente investigadas e resolvidas; Gabriela Oliveira da Silva: contribui na sua elaboração com as seguintes atividades: contribuições substanciais para a concepção ou delineamento do estudo; ou a aquisição, análise ou interpretação dos dados do trabalho; Antonia Angulo-Tuesta contribui na elaboração de versões preliminares do artigo e aprovação final da versão a ser publicada; Ivana Cristina de Holanda Cunha Barreto: contribui na elaboração de versões preliminares do artigo e aprovação final da versão a ser publicada; Mauro Niskier Sanchez: contribui na elaboração de versões preliminares do artigo, revisão crítica de importante conteúdo intelectual e aprovação final da versão a ser publicada; Luiz Odorico Monteiro: contribui na elaboração de versões preliminares do artigo e aprovação final da versão a ser publicada; Leonor Maria Pacheco Santos: contribui na sua elaboração com as seguintes atividades: elaboração de 
versões preliminares do artigo ou revisão crítica de importante conteúdo intelectual; aprovação final da versão a ser publicada; concordância em ser responsável por todos os aspectos do trabalho, no sentido de garantir que as questões relacionadas à exatidão ou à integridade de qualquer parte da obra sejam devidamente investigadas e resolvidas.

Financiamento: Chamada Pública MCTI/CNPq/CT-Saúde/MS/SCTIE/Decit No 07/2020

\section{Resumo}

Analisa-se a cobertura midiática sobre ciência e Sistema Único de Saúde (SUS) durante a COVID19, à luz da sociedade informatizada. Nota-se a presença dessas pautas no cotidiano, justificada pelo interesse da população na exploração dos temas científicos e na atuação do SUS no enfrentamento à pandemia. Hoje, diante do grande espaço de debates proporcionado pelas Tecnologias da Informação e Comunicação, surgem novos atores e necessidades de proposição de respostas rápidas a uma sociedade cada vez mais conectada. Ressalta-se a crescente presença e valorização de evidências científicas, da importância e dos desafios do SUS na mídia, apesar do interesse de parcela da sociedade em difundir notícias falsas que geram desinformação na rede. Ademais de informar sobre ações para evitar a propagação da COVID-19, cientistas cotidianamente são demandados pela mídia, para produzir narrativas robustas, divulgar conhecimentos científicos que comprovam medidas sanitárias exitosas, oferecer esclarecimentos a respeito de informações distorcidas ou fantasiosas e divulgar as respostas do SUS diante desta crise sanitária e humanitária. Manter-se presente na mídia deve ser uma meta para cientistas, sociedades científicas e lideranças do SUS, com a clareza da importância de disseminar a ciência, combater o obscurantismo e ampliar a sustentação popular ao nosso sistema universal de saúde.

Palavras-chave (DECS): Meios de Comunicação de Massa; Difusão do Conhecimento Científico e Técnico através das TIC; Compartilhamento de Informação; Acesso à Informação de Saúde; Comunicação em Saúde; COVID-19. 


\begin{abstract}
Media coverage about science and the Unified Health System (SUS) during COVID-19 is analyzed, in the light of the computerized society. These subjects are daily in the media, justified by the population's interest in the exploration of scientific themes and in SUS's actions to tackle the pandemic. Today the Information and Communication Technologies are new actors providing space for debate; the need to propose quick responses to an increasingly connected society are emerging. The growing presence and appreciation of scientific evidence, the importance and challenges of SUS in the media are highlighted, despite the interest of part of society in spreading false news that generate misinformation on the network. In addition to reporting on actions to prevent the spread of COVID-19, scientists are daily demanded by the media, to produce robust narratives, to disseminate scientific knowledge that prove successful sanitary measures, to offer clarifications regarding distorted or fanciful information and to disseminate SUS responses, to face this health and humanitarian crisis. Staying present in the media should be a goal for scientists, scientific societies and SUS leaders, with the clarity of the importance of disseminating science, combating obscurantism and expanding popular support for our universal health system.
\end{abstract}

Key words (DECS): Mass media. Information Dissemination. Information Exchange. Access to Information. Health Communication. COVID-19 


\section{Introdução}

O Brasil é uma das maiores potências mundiais em consumo de informação on-line, com presença marcante no cenário das redes sociais. Segundo informações da pesquisa TIC Domicílios de 2019, três em cada quatro brasileiros acessam a internet, o que equivale a 134 milhões de pessoas ${ }^{\mathbf{1}}$. Embora a quantidade de usuários e os serviços online utilizados tenham aumentado, ainda persistem diferenças de acesso associadas a renda, gênero, raça/cor/etnia e regiões. Essa estrutura atuante, construída nos meios digitais, têm se tornado cada dia mais um misto de palco para reclamações, discursos inflamados, notícias falsas e reinvindicações de cunho político e social.

Mesmo com a criação do Marco Civil da Internet, em 2014, que estabelece princípios, garantias, direitos e deveres para o uso da internet no Brasil, a participação de brasileiros/as no meio digital ainda encontra diversos desafios de normatização. O maior deles, atualmente, a exemplo do que acontece no mundo, é a forte onda de propagação das fake news, para as quais esse Marco tem se demonstrado insuficiente para combater com o rigor necessário. Portanto, urge pensar mecanismos de retenção, adaptação e sustentabilidade de toda essa informação gerada, como propor mecanismos regulatórios ou auto-regulatórios, para coibir as notícias falsas a fim de resgatar a credibilidade das Tecnologias da Informação e Comunicação. Nesse ponto, acaba restando ao receptor dessas informações, verificar a fonte, os dados e os interesses envolvidos por trás de cada conteúdo.

Apesar dos conflitos de diversas ordens, ressaltam-se os avanços que a massificação do uso da internet trouxe ao país, de modo que hoje ela concentra boa parte das discussões, tendo participação direta em decisões, posições e até definição dos rumos no que diz respeito ao posicionamento de pessoas e de grupos no meio digital. O relatório "Digital in 2020" mostra uma visão completa do panorama digital no Brasil: "Altamente conectados e heavy users de dispositivos móveis”, estas são as palavras que descrevem o uso da internet no Brasil, que inclui o tempo que os brasileiros passam online, quais aplicativos acessam, entre outros. Alguns dados chamam atenção, como a existência de 140 milhões de usuários de mídias sociais ativos, que utilizam a internet diariamente, por $9 \mathrm{~h} 17 \mathrm{~m}$ em média ${ }^{2}$.

Em 2020, a pandemia da COVID-19 alterou as formas com que os veículos de comunicação planejam seus temas de interesse. Na contramão de anos anteriores, a imprensa de modo geral, passa a oferecer cobertura ampla de temas voltados à Ciência, Saúde e cuidados preventivos. Os termos do jargão epidemiológico: número de casos, óbitos, média móvel, ensaio clínico, placebo, 
eficácia, cepas/ variantes, cobertura vacinal, Insumo Farmacêutico Ativo (IFA), como exemplos, tornaram-se palavras cotidianas. Amplificou-se a cobertura jornalística e concentrou-se maior volume de escritos em editoriais específicos sobre ciência, o que mudou significativamente o dia a dia das redações dos grandes jornais e veículos de imprensa em termos da veiculação destes temas. Os principais jornais do país trazem em manchetes de capa, os desdobramentos da crise sanitária, de forma evidente e reiterada, com o panorama do número de pessoas infectadas e mortas, a ocupação de leitos hospitalares, em especial de UTI, o acesso e organização para a vacinação, as extenuantes condições de trabalho dos profissionais de saúde, os efeitos na saúde e os impactos sociais e econômicos causados pela crise de forma desigual na população. Neste contexto, esse ensaio busca analisar a cobertura midiática sobre ciência e SUS durante a pandemia de COVID-19.

\section{Vírus, informação e desinformação}

Quando abordamos a cobertura feita pela imprensa brasileira, em se tratando do combate a um vírus, notamos semelhanças e diferenças importantes em períodos diversos da história. No século passado a gripe espanhola espalhou-se muito rápido e matava em poucos dias; a estimativa é que cerca de 35 mil pessoas morreram vítimas da doença no Brasil; a gripe, inclusive, ceifou a vida do presidente eleito Rodrigues Alves ${ }^{3}$. A imprensa brasileira à época, tinha uma característica informativa e certo viés educativo, com intuito de disseminar orientações sobre o uso de máscaras e a importância de manter o isolamento social necessário para frear o contágio. Em São Paulo, eram publicadas uma série de recomendações para ensinar a população a se prevenir e listavam as medidas preventivas como "fugir das aglomerações", "não frequentar teatros e cinemas" e "não fazer visitas", além de "tomar cuidados higiênicos"4.

A história também se repete quanto à presença de movimentos anti-máscara, protestos contra as medidas de isolamento e medicamentos sem eficácia. Eram anunciados, na imprensa, remédios para a influenza espanhola como a "Grippina", produzida pelo laboratório homeopático Alberto Seabra, em São Paulo, que prometia estimular as defesas do organismo. Em Porto Alegre, o laboratório Sanitas, que gozava de prestígio científico, comercializava comprimidos de “Oxyform”, anunciado como remédio profilático e curativo da influenza espanhola; o laboratório EKA produzia o "Formagem", para atenuar os sintomas e apregoava a sua composição: "à base de formaldeído [formol], o mais poderoso desinfectante conhecido, desinfecta radicalmente a boca e as vias respiratórias [...] De paladar agradável, é absolutamente inofensivo à saúde"3. 
De acordo com outros autores, em ambas as pandemias se observa intenso debate público sobre a doença, a morte, as formas de infecção e as medidas governamentais adotadas. Ainda que em conjunturas sociais, econômicas e políticas diferentes, tanto na gripe espanhola como na COVID19 desvelam-se questões semelhantes, milhares de pessoas mortas, especialmente, entre os setores mais pobres da população, suspensão de cerimônias fúnebres, adoção do isolamento social, paralização de atividades produtivas, a irresponsabilidade sanitária dos governantes e as fragilidades dos serviços de saúde 5 .

No entanto, o lapso temporal de cem anos entre as duas pandemias, gripe espanhola (1918) e a COVID-19 (2020), trazem à tona o quanto o acesso às novas tecnologias oferece a chance de produção e propagação de informação e desinformação (fake news), de maneira mais ágil e capilarizada.

A disseminação e o alcance de fake news podem ser ilustradas pelo bizarro episódio de incêndio e destruição de dezenas de torres de celular 5G na Inglaterra, em abril de 2020, baseado na teoria conspiratória vinculando a disseminação da COVID-19 à presença destas torres ${ }^{6}$. Um estudo baseado em Análise de Redes Sociais, examinou milhares de tweets para descrever a dinâmica da disseminação dessa notícia falsa ${ }^{7}$. Em janeiro de 2020 foram identificadas as primeiras postagens com essa teoria conspiratória, quando vídeos e notícias eram intensamente compartilhados. Portais de verificação independentes concluíram que a base dessas afirmações era falsa, mas isso não impediu sua rápida propagação nas redes sociais. Os pesquisadores analisaram as principais fontes de informação dos usuários, concluindo que a maioria era de sites de notícias "falsas" ou apresentados como veículos "alternativos". O InfoWars, site popular na difusão de teorias da conspiração, baseado nos EUA, foi a fonte da web mais popular entre os divulgadores do tema no Twitter. Segundo os autores, faltou uma figura de autoridade que combatesse ativamente essa desinformação. Muitas plataformas de mídia social fornecem aos usuários a capacidade de relatar conteúdo impróprio, mecanismo que deve ser incentivado para combater as fake news ${ }^{7}$.

A análise sobre as notícias falsas relacionadas com a COVID-19 mais disseminadas nas redes sociais, a partir das notificações recebidas no aplicativo brasileiro "Eu Fiscalizo" demonstrou que 65\% delas ensinavam métodos caseiros para prevenir o contágio; $20 \%$ mostravam métodos caseiros para curar a doença, 5\% mencionavam golpes de arrecadações para instituição de pesquisa e 4,3\% era sobre o uso do novo coronavírus como estratégia política ${ }^{\mathbf{8}}$. Os principais canais de compartilhamento de fake news eram o WhatsApp (73,7\%) e Instagram (15,8\%). A maioria das 
mensagens falsas que circulam pelo WhatsApp (71,4\%), citavam a Fiocruz como fonte de textos sobre medidas de proteção e enfrentamento à doença ${ }^{8}$.

O reflexo deste movimento de pessoas que espalham notícias falsas nas redes sociais, seja desmentindo-as, satirizando ou fazendo-as circular sem checar a veracidade, altera de maneira profunda não só a cobertura jornalística realizada pelos grandes canais de imprensa, mas também, o trabalho feito pelos jornalistas, considerando que essas notícias podem influenciar o comportamento das pessoas e colocar em risco a adesão aos cuidados cientificamente comprovados ${ }^{8}$.

No contexto da pandemia de COVID-19 verifica-se que significativa parcela da população (50\%) acredita em notícias falsas sobre a doença; nove em cada 10 brasileiros/as entrevistados/as leram ou ouviram pelo menos uma informação falsa; sete em cada 10 consideraram verdadeira pelo menos um conteúdo desinformativo sobre a pandemia9 e a maioria da população não reconhece quando uma mensagem é falsa ${ }^{\mathbf{1 0}}$.

Uma matéria recente do Jornal El País, sugere o impacto das fake news, que aliado à falta de doses e falhas na estratégia brasileira, aparece como um dos principais fatores que levam os brasileiros a não voltar para tomar a segunda dose da vacina contra o Coronavírus. Além disso, cidades que calculam mal a segunda aplicação e falhas estratégicas e desinformação contribuem para o abandono vacinal e podem comprometer proteção coletiva na campanha brasileira de imunização, dizem especialistas ${ }^{\mathbf{1 1}}$.

O sociólogo Boaventura de Souza Santos afirma "que as epidemias tendem a ser menos letais em países democráticos, devido à livre circulação de informação", assim como apontado pela revista "The Economist". No entanto, também indica a vulnerabilidade dos sistemas democráticos às fake news. Ao passo que o sistema favorece a livre circulação de informações a respeito do vírus e cuidados necessários, também permite a rápida disseminação de informações inverídicas. $\mathrm{O}$ autor sugere ser necessário "imaginar soluções democráticas, assentes na democracia participativa, ao nível dos bairros e das comunidades e na educação cívica" de modo a incentivar os sentimentos de solidariedade e participação, para assim fazer frente à desinformação trazida por meios digitais $^{12}$. 


\section{O Sistema Único de Saúde na mídia durante a COVID-19}

O SUS foi instituído pela Constituição Federal de 1988, em seu artigo 196, como garantia do direito à saúde e dever do Estado mediante "políticas sociais e econômicas abrangentes que reduzam o risco de doenças e agravos e ao acesso universal e igualitário às ações e serviços para sua promoção, proteção e recuperação" ${ }^{13}$. A implantação do SUS começa após a promulgação da Lei Orgânica da Saúde (Lei $n^{\circ}$. 8.080/1990), orientado por princípios e diretrizes para o funcionamento: a universalização de acessos em todos os níveis de assistência, a igualdade na assistência à saúde, sem preconceitos ou privilégios, a integralidade da assistência, a participação da comunidade e a descentralização político-administrativa. Funciona como um dos maiores sistemas universais de saúde pública do mundo com distribuição de ações e serviços por níveis de atenção de acordo com as necessidades diferenciadas de saúde em todo o país. A organização de redes de atenção à saúde requer esforços que sobrepõem ao investimento financeiro. Saúde requer investimentos, humano, material e informativo, e custa caro. Essa não é uma realidade apenas brasileira. O novo cenário globalizado exige a manutenção de conteúdos informacionais, além do acompanhamento e transparência em todas as ações. Dessa maneira, o SUS deve ser constante fonte de informação, os resultados de suas ações devem ser amplamente divulgados pelo seu caráter universal e público.

Neste ensaio interessa analisar a cobertura midiática de assuntos referentes ao SUS, que, de modo geral, demonstra um retrato negativo do sistema. É o que aponta o médico Paulo Dantas, membro do Conselho Honorário do Conselho Nacional de Secretarias Municipais de Saúde (Conasems), no dossiê "Somos Todos SUS”. Segundo ele, a grande mídia é a responsável pela população não conhecer o SUS em sua integralidade: "Geralmente o foco é a doença e as ações curativas, especialmente a hospitalar, com destaque para o que não funciona bem" e continua: "as notícias priorizam as insuficiências e as mazelas que ainda existem no sistema ${ }^{\mathbf{1 4}}$.

É o que também observa uma análise da cobertura midiática no relatório publicado pelo Banco Mundial, em 2013, intitulado "20 anos de construção do sistema de saúde no Brasil: Uma avaliação do Sistema Único de Saúde". O relatório se propôs a analisar a trajetória do SUS, sua construção, desafios e resultados nos vinte anos de existência. Segundo o Relatório as notícias "majoritariamente, focaram em torno das fragilidades do sistema, que, no entanto, foram relatados pelos autores do documento como desafios a serem enfrentados”. A percepção dos usuários sobre o Sistema Único de Saúde está muitas vezes limitada aos recortes trazidos pela grande mídia. Neste sentido, mensura-se a importância de uma cobertura imparcial e mais abrangente. "Mesmo com o 
largo acesso à televisão, internet, rádio e outros aparatos, o debate necessário está restrito à superficialidade dos recortes do que é lançado ao público"15. Esses recortes por sua vez, de acordo com o médico Paulo Dantas, são uma seleção fruto da monopolização midiática que não reconhece o devido valor do $\mathrm{SUS}^{\mathbf{1 4}}$. Em parte, isto ocorre porque de maneira geral, a notícia tida como negativa, ou mesmo polêmica, chama mais atenção culturalmente. A cobertura midiática funciona sob o prisma da chamada Agenda-Setting, onde estão dispostos temas de interesse pautados pelo público de maneira consciente e inconsciente. McCombs (apud Castro, 2014) argumenta que os membros da audiência não são seres autômatos à espera de serem programados pelos veículos de notícia. O papel central que a hipótese atribui aos veículos noticiosos se justifica, então, pela capacidade deles em definir itens para a agenda pública. “...A informação fornecida pelos veículos noticiosos joga um papel central na constituição de nossas imagens da realidade"16.

O que explica essa predileção pelas mazelas do SUS na mídia é o que alguns pesquisadores apontam como sendo valores-notícias "que impactam de maneira direta a cobertura midiática e a exploração ou exclusão de repertórios”. Portanto, para os autores, o enfoque da notícia nesses casos, leva em conta, por exemplo, o número elevado de pessoas afetadas por um problema de saúde ou por uma medida política em matéria de saúde, que por consoante estariam interessadas no escrito publicado pelo jornal ou revista. Logo, nota-se que a produção jornalística se alimenta e, ao mesmo tempo, alimenta o cotidiano. O que se convenciona ser os critérios de noticiabilidade colabora para que se escolham, entre vários fatos, aqueles que podem ser transformados em notícia, "conferindo a esses estratos do real ou status de realidade". Os critérios de noticiabilidade colaboram para a construção social do que se entende por realidade ${ }^{17}$.

\section{A ciência na mídia durante a COVID-19}

O surto de coronavírus envolveu o reconhecimento do jornalismo como uma instância essencial nas sociedades do século XXI. Neste caso, os dados, tanto sobre o consumo quanto sobre a avaliação da credibilidade da cobertura jornalística, reafirmam a alta relevância social do sistema midiático no nosso mundo em momentos críticos ${ }^{18}$. Outros campos do conhecimento também ganharam verdadeira lente de aumento nos últimos anos, como a Pesquisa, Desenvolvimento e Inovação (PD\&I), por trazerem as respostas que a mídia precisava publicizar.

Como exemplo dessa exposição da ciência na mídia, temos estudos que analisaram como a mobilização da comunidade científica brasileira para atender às necessidades mais urgentes da COVID-19, resultou em projetos de PD\& $\mathrm{I}^{\mathbf{1 9 , 2 0}}$. As iniciativas, que em geral não contavam com 
financiamentos novos, tiveram efeitos práticos na mitigação dos efeitos da pandemia e alguma repercussão midiática ${ }^{21,22}$. É importante enfatizar que a resposta das universidades só foi possível devido a décadas de investimento na criação de um verdadeiro patrimônio nacional, representado pelas universidades públicas e institutos de pesquisa como a Fiocruz e o Butantã, com equipes compostas por funcionários públicos qualificados ${ }^{19}$. Mesmo com verbas para pesquisa em franco declínio após 2015, a capacidade instalada foi posta em marcha, numa velocidade surpreendente, registrando-se quase 800 projetos de PD\&I até 15 de maio de 2020. Os autores reforçam a necessidade de proteger o sistema brasileiro de ciência, tecnologia e inovação de políticas de austeridade, que minimizam a importância da saúde e o conhecimento como investimentos fundamentais para a sociedade brasileira ${ }^{\mathbf{1 9}}$.

Outro ponto em evidência na mídia diz respeito à ciência e soberania nacional, frente ao desafio da COVID-19. O professor Isaac Roitman, membro da Academia Brasileira de Ciências, escreveu no Monitor Mercantil, que a pandemia ativou o sinal vermelho devido ao desconhecimento sobre a biologia do vírus, sua vertiginosa propagação, altas taxas de mortalidade e pelos efeitos sociais e econômicos; cientistas de todo o planeta tentam desenvolver vacinas para a prevenção da COVID-19. Considera ainda que a inserção do Brasil na Era do Conhecimento é uma questão de soberania, já que o país dispõe de instituições científicas e tecnológicas com tradição, de um robusto sistema de pós-graduação e está preparado para implantar o desenvolvimento científico com humanismo ${ }^{\mathbf{2 3}}$. O jornal Valor Econômico publicou matéria do Presidente da Confederação Nacional da Indústria (CNI), Robson Braga Andrade, ponderando que crise sanitária tornou indiscutível a relevância de ciência, tecnologia e inovação, para que as sociedades possam responder às pandemias e outras ameaças. Cita ainda que a falta de financiamento público em PD\&I e a retração do incipiente investimento privado por empresas inovadoras, coloca o desenvolvimento e a soberania em risco para enfrentar a crise da saúde pública causada pela COVID-1924. Ênio Pontes, do PROIFES, entidade que representa professores universitários federais, discute que na Economia do Conhecimento, o capital científico se tornou um importante vetor para o desenvolvimento e que diante dos desafios regionais e globais, o potencial científico e tecnológico se sobressai como fator determinante para o pleno exercício da soberania nacional ${ }^{25}$.

Observa-se o olhar da sociedade em torno da abordagem de temas relacionados à ciência de modo que a imprensa opera como grande partícipe deste processo. Talvez porque em grande parte, a manchete e as chamadas atraiam os olhares, porém a audiência não esteja debruçada na leitura dos fatos na íntegra e no acompanhamento fidedigno dos desdobramentos que ocorrem de maneira 
cada vez mais rápida. Ainda assim, há uma conjunção de fatores para acreditar na maior confiança dispensada pela sociedade à comunidade científica.

Pesquisa sobre o impacto da COVID-19 na percepção pública da ciência, aponta que dos mil brasileiros entrevistados, $66 \%$ disseram confiar ou confiar muito nos cientistas como fonte de informação, $54 \%$ afirmaram que a ciência beneficia ou beneficia muito a sociedade e $80 \%$ declararam considerar as vacinas como seguras $^{\mathbf{2 6}}$. Portanto não há uma crise de confiança dos brasileiros em relação à ciência. No entanto permanece uma desconexão entre um mundo abstrato da ciência, interessante e curioso para muitos, e a vida cotidiana das pessoas, da qual a ciência estaria, ao menos aparentemente, excluída. Parece haver na sociedade brasileira um distanciamento, apatia e indiferença no que diz respeito à prática cotidiana da ciência ${ }^{\mathbf{2 6}}$.

Do ponto de vista da sociedade, a ciência é vista como fator preponderante na coleta e absorção de informações importantes. Além disso, pondera-se mais pontos positivos do que negativos na proposição e exposição de estudos, dados e na própria disseminação do conhecimento. O debate e a massificação da Ciência e Tecnologia foram objeto da pesquisa "Percepção Pública da C\&T no Brasil - 2019”, que demonstrou: “A visão positiva que a sociedade brasileira tem sobre a ciência e a tecnologia se mantém ${ }^{27}$. Os resultados mostraram que $73 \%$ dos entrevistados acham que C\&T trazem só benefícios ou mais benefícios que malefícios para a sociedade. Os dados apontam que, apesar das profundas mudanças sociopolíticas dos últimos anos, os brasileiros mantêm uma visão otimista em relação à área". Ao passo que o perfil da representação dos cientistas na cultura brasileira também foi se mantendo, ao longo dos anos, substancialmente positivo: são vistos principalmente como pessoas inteligentes que fazem coisas úteis à humanidade por $41 \%$ dos entrevistados ${ }^{27}$.

Alguns autores destacam que falta estrutura profissionalizada de comunicação para dar suporte ao trabalho de divulgação dentro das instituições de ciência e tecnologia. Assim como a insensibilidade dos profissionais de imprensa ao processo de produção científica, o método científico e a cultura científica em particular. Algo que pode estar ligado diretamente à falta de formação adequada para a cobertura da editoria de ciências. Mas essa superficialidade na cobertura da mídia sobre pesquisas e descobertas científicas teve uma mudança brusca com o enfrentamento de uma pandemia em plena era das mídias sociais. No entanto, mesmo ao reconhecer a existência da cobertura científica na mídia, é notável que são poucos os veículos de informação geral que contam com editorias especializadas e "as que existem, quase sempre, têm uma estrutura acanhada, 
sendo, portanto, incapazes de acompanhar a dinâmica da produção científica e tecnológica brasileira e oferecer-lhe uma cobertura atualizada e consistente"28.

O jornalismo reaparece como uma das camadas mais importantes ao se tratar da tradução do conhecimento à sociedade. A ciência é o instrumento por meio do qual é possível dar as respostas a muitas necessidades e aos questionamentos da sociedade, pois como ressaltam Belens e Porto, "a produção científica responde as questões do seu tempo"29. Dessa maneira, à medida que o jornalismo permeia temas científicos e as questões de saúde, caminha lado a lado com a educação - que opera o primeiro lugar desse modelo de aprendizagem social. Esse caráter pedagógico, acaba gerando "referências para a ação e para a mudança de atitudes e mentalidades nos indivíduos"30.

O aprofundamento dessas informações tem sustentação na evolução da comunicação à distância, que passou pelo uso do telégrafo, telefone, satélite e hoje a rede mundial de computadores. "Essas tecnologias modernas facilitaram a difusão científica e o acesso a um maior número de pessoas ao conhecimento"29. Desta maneira, a divulgação científica por meio do jornalismo científico, pode agir como elemento moderador entre a ciência e o público leitor.

\section{Conclusões}

Em decorrência da pandemia do coronavírus, nota-se uma mudança da cobertura midiática em torno da ciência, da saúde e do SUS. Apesar de ainda encontrar-se matérias com críticas sobre a gestão da saúde, como a falta de leitos de UTI, por exemplo, o SUS, enquanto sistema público, foi elevado a um novo patamar. Como exemplo, o trabalho realizado pelas equipes do SUS tem sido alçado, com frequência, ao status de heroico e solidário. Pautas quase que cotidianas discutem os riscos à soberania nacional decorrentes da enorme dependência do Brasil aos insumos importados na área da saúde (matéria prima para vacinas/IFA, medicamentos, equipamentos, EPI). Destacamse também pautas sobre os investimentos cronicamente insuficientes para o SUS e o prejuízo de recentes medidas de austeridade fiscal que incidem sobre ciência e a saúde. O potencial da ciência, tecnologia e inovação nas universidades públicas e institutos de pesquisa como Fiocruz e Butantã ganharam destaque. Resta ainda o enorme desafio de propor mecanismos regulatórios e/ou autoregulatórios, para coibir as notícias falsas de modo a resgatar a credibilidade das informações veiculadas na internet. Manter-se presente na mídia deve ser uma meta para cientistas, sociedades científicas, bem como as lideranças do SUS para garantir e manter um potente canal de comunicação com a sociedade, com a clareza da importância de disseminar a ciência, combater o obscurantismo e ampliar a sustentação popular ao nosso sistema universal de saúde. 


\section{REFERÊNCIAS}

1.CETIC. Centro Regional e Estudos para Desenvolvimento da Sociedade da Informação. Pesquisa TIC Domicílios, 2019. [acesso em 2021 mar 29]. Disponível em:

https://cetic.br/pt/noticia/tres-em-cada-quatro-brasileiros-ja-utilizam-a-internet-aponta-pesquisa$\underline{\text { tic-domicilios-2019/ }}$

2.We are social/ Hootsuite. Relatório Digital in 2020. [acesso em 2021 mar 26]. Disponível em: https://www.amper.ag/post/we-are-social-e-hootsuite-digital-2020-report-completo

3.Biernath, A. Como os presidentes brasileiros lidaram com a gripe espanhola no início do século 20? [internet]. BBC News Brasil. 2021 Fev. 14 [acesso em 2021 abr 25]. Disponível em: https://www.bbc.com/portuguese/brasil-

56031995\#: :text=\%220\%20Brasil\%20seria\%20sede\%20do,pico\%20de\%20mortes\%22\%2C\% $\underline{\text { 20relata }}$

4.Helal Filho W. Coronavírus resgata medidas restritivas da epidemia de gripe espanhola, que matou até o presidente do Brasil. [internet]. O Globo. 2020 Mar. 18. [acesso em 2021 mar 24]. Disponível em: https://blogs.oglobo.globo.com/blog-do-acervo/post/coronavirus-resgatarecomendacoes-e-medidas-restritivas-da-epidemia-de-gripe-espanhola.html

5.Kind L, Cordeiro R. Narrativas sobre a morte: a gripe espanhola e a COVID-19 no Brasil. Psicologia \& Sociedade, 2020;32:e020004. [internet]. [acesso em 2021 apr 13]. Disponível em: https://www.scielo.br/pdf/psoc/v32/1807-0310-psoc-32-e020004.pdf

6. Satariano A, Alba D. Burning Cell Towers, out of baseless fear they spread the virus. [internet]. The New York Times [April 11, 2020] [acesso em 2021 apr 13]. Disponível em: https://www.nytimes.com/2020/04/10/technology/coronavirus-5g-uk.html

7.Ahmed W, Vidal-Alaball J, Downing J et al. COVID-19 and the 5G Conspiracy Theory: Social Network Analysis of Twitter Data. J Med Internet Res. 2020;22(5):e19458. [acesso em 2021 apr 13]. Disponível em: https://www.ncbi.nlm.nih.gov/pmc/articles/PMC7205032/\#app1

8. Gualhardi CP, Freire NP, Minayo MCS et al. Fato ou Fake? Uma análise da desinformação frente à pandemia da Covid-19 no Brasil Ciênc. saúde coletiva 2020;25(suppl 2):4201-4210. [acesso em 2021 apr 13]. Disponível em: https://www.scielo.br/pdf/csc/v25s2/1413-8123-csc-25$\underline{\text { s2-4201.pdf }}$ 
9. Coletiva.Net. Pesquisa alerta que sete a cada dez brasileiros acreditam em fake news sobre Covid-19 [internet]. 2020 [acesso em 2021 abr 19]. Disponível em:

https://coletiva.net/noticias/pesquisa-alerta-que-sete-em-cada-dez-brasileiros-acreditam-em-fakenews-sobre-covid-9,358082.jhtml

10. Agência Lupa. Na pandemia, criminosos usam falsas ofertas e benefícios para aplicar golpes [internet]. 2020 [acesso em 2021 abr 19]. Disponível em:

https://piaui.folha.uol.com.br/lupa/2020/07/21/coronaverificado-golpes-pandemia/

11. Jucá, B. De 'fake news' à desigualdade, o que leva brasileiros a não voltarem para tomar a segunda dose da vacina. [internet]. El Pais 2021 Abr. 19 [acesso em 2021 abr 21]. Disponível em: https://brasil.elpais.com/brasil/2021-04-20/de-fake-news-a-desigualdade-o-que-levabrasileiros-a-nao-voltarem-para-tomar-a-segunda-dose-da-vacina.html

12. Santos, BS. A Cruel Pedagogia do Vírus. [internet]. Coimbra: Edições Almedina; 2020. [acesso em 2021 abr 13]. Disponível em: https://www.cidadessaudaveis.org.br/cepedoc/wpcontent/uploads/2020/04/Livro-Boaventura-A-pedagogia-do-virus.pdf

13. Brasil. Constituição, 1988. Constituição da República Federativa do Brasil. Brasília: Senado Federal; 1988.

14. Carvalho T. Sistema faz parte do dia a dia de todos os brasileiros, mas não é reconhecido em suas diversas dimensões. Dossiê: Somos Todos SUS. Revista Conasems, edição 63. Novembro e dezembro de 2015. [acesso em 2021 abr 19]. Disponível em: https://www.conasems.org.br/wpcontent/uploads/2016/03/revista_conasems_edicao63_tela.pdf

15. Souza SC. A mídia e o relatório do Banco Mundial sobre o SUS: um reflexo impreciso. 2015. Trabalho de Conclusão de Curso. [Graduação em Saúde Coletiva] [internet] - Universidade de Brasília. Orientador: Everton Nunes da Silva. 24p. [acesso em 2021 abr 9]. Disponível em: https://bdm.unb.br/bitstream/10483/10829/1/2015_SheylaCardosodeSouza.pdf

16. MC Combs 2004 apud CASTRO, Davi de. Agenda-setting: hipótese ou teoria? Análise da trajetória do modelo de Agendamento ancorada nos conceitos de Imre Lakatos [internet]. [Porto Alegre]: Intexto, UFRGS, 2014; 31:197-214. [acesso em 2021 abr. 20]. Disponível em: https://seer.ufrgs.br/intexto/article/viewFile/46390/32217 
17. Langbecker A, Castellanos MEP, Catalán-Matamoros D. Quando os sistemas públicos de saúde são notícia: uma análise comparativa da cobertura jornalista no Brasil e na Espanha. Ciênc. saúde coletiva 2020; 25(11): 4281-4292. [Internet]. [acesso em 2021 mar 27]. Disponível em: https://www.scielo.br/pdf/csc/v25n11/1413-8123-csc-25-11-4281.pdf

18. Cabrera A, Martins C, Cunha IF. A cobertura televisiva da pandemia de COVID-19 em Portugal: um estudo exploratório. Revista Media e Jornalismo 2020;20(37):185-204. [Internet]. [acesso em 2021 abr 19]. Disponível em: https://impactum-journals.uc.pt/mj/article/view/2183$\underline{5462 \_37 \_10}$

19. Rosa MFF, Silva EN, Pacheco $C$ et al. Direct from the COVID-19 crisis: research and innovation sparks in Brazil. Health Res Policy Sys 2021;19:10 [doi 10.1186/s12961-020-00674x]. [acesso em 2021 apr 13]. Disponível em: https://health-policysystems.biomedcentral.com/track/pdf/10.1186/s12961-020-00674-x.pdf

20._Arrais CA, Corcioli G, Medina GS et al. The role played by public universities in mitigating the coronavirus catastrophe in Brazil: solidarity, research and support to local governments facing the health crisis. Front. Sociol. 2021;6:610297. [acesso em 2021 abr 19]. Disponível em: https://www.frontiersin.org/articles/10.3389/fsoc.2021.610297/full

21. Santos LMP. Pesquisa e inovação sobre Covid-19 disparam nas universidades públicas. Ecos/UNB. [internet]. Aula Pública em 14 de julho de 2020: O desenvolvimento tecnológico em tempos de pandemia. [acesso em 2021 abr 19]. Disponível em: https://www.youtube.com/watch?v=VWnHpADtoOU\&t=2272s

22. Melo C. Estudo da UFG destaca papel das universidades na mitigação da pandemia. Jornal UFG 16/03/21. [acesso em 2021 abr 19]. Disponível em: https://jornal.ufg.br/n/139727estudo-da-ufg-destaca-papel-das-universidades-na-mitigacao-da-pandemia

23. Roitman I. A importância da ciência transcende a obtenção de vacinas para a COVID-19. Publicado originalmente no Monitor Mercantil em 2020 set. 10. [acesso em 2021 abr 19]. Disponível em: https://noticias.unb.br/artigos-main/4454-a-importancia-da-ciencia-transcende-aobtencao-de-vacinas-para-a-covid 
24. Andrade RB. Déficit na inovação coloca a soberania em risco [internet]. Valor Econômico. 2020 Mai. 06 [acesso em 2021 abr 19]. Disponível em:

https://valor.globo.com/opiniao/coluna/deficit-na-inovacao-coloca-a-soberania-em-risco.ghtml

25. Pontes E. Ciência e soberania. PROIFES Federação de sindicatos de professores e professoras de Instituições Federais de Ensino Superior e de Ensino Básico Técnico e Tecnológico. [internet] 2021. [acesso em 2021 abr 19]. Disponível em: https://www.proifes.org.br/artigos/ciencia-esoberania/?fbclid=IwAR0xGuZD9ZsOPbFMV63hbph5oNXSYz9y6xV_yRRSyWQJViMVxQb2lx66cA\#.YGX1Tq_Yn6M.facebook

26. Almeida, Carla da Silva. 'Make science great again'? O impacto da Covid-19 na percepção pública da ciência. [internet]. DILEMAS: Revista de Estudos de Conflito e Controle Social - Rio de Janeiro - Edição Especial: Reflexões na Pandemia 2020 - pp. 1-24. [acesso em 2021 abr 19]. Disponível em: https://www.arca.fiocruz.br/bitstream/icict/41506/2/ALMEIDA-make-science$\underline{2020 . p d f}$

27. Centro de Gestão e Estudos Estratégicos - CGEE. Percepção pública da C\&T no Brasil 2019. Resumo executivo. Brasília, DF: 2019. 24p. [acesso em 2021 abr 19]. Disponível em: https://www.cgee.org.br/documents/10195/734063/CGEE_resumoexecutivo_Percepcao_pub_CT.pdf

28. Bueno, Wilson da Costa. Jornalismo científico no Brasil: os desafios de uma longa trajetória. IN. Porto, Cristiane de Magalhães (Org.). Difusão e cultura científica: alguns recortes. Salvador: EDUFBA, 2009. $230 \mathrm{p}$.

29. Belens, Adroaldo de Jesus; Porto, Cristiane de Magalhães. Ciência e tecnologia, uma abordagem histórica na sociedade da informação. IN. Porto, Cristiane de Magalhães (Org.). Difusão e cultura científica: alguns recortes. Salvador: EDUFBA, 2009. 230 p.

30. Henriques MS. (org) Comunicação e estratégias de mobilização social. Belo Horizonte: Autêntica; 2004. 